\section{Detection of Pstl RFLP in human ADA by the polymerase chain reaction}

\author{
H.Ikegami, M.Fukuda, Y.Kawaguchi, Y.Fujioka and \\ T.Ogihara \\ Department of Geriatric Medicine, Osaka University \\ Medical School, 1-1-50 Fukushima, Osaka 553, Japan
}

Source/Description: Two primers derived from the sequence flanking the polymorphic PstI site in intron 2 of the adenosine deaminase (ADA) gene $(1,2)$ were selected for polymerase chain reaction (PCR) to amplify a $356 \mathrm{bp}$ fragment that spans the PstI polymorphism. Polymorphism was detected by PstI digestion of the PCR product.

Primer Sequences

Forward primer: 5'-AGAACTGCATGTCCACCTAG-3'

Reverse primer: 5'-AACTACCTTCATGCACGTATG-3'

Polymorphism: K1 allele that lacks the polymorphic PstI site generates a full-length 356 bp fragment on PstI digestion. K2 allele that contains the PstI site generates fragments at 239 and 117 bp on PstI digestion.

Frequency: Estimated from 55 unrelated Japanese individuals. K1: 0.20

$\mathrm{K} 2: 0.80$

Chromosomal Localization: The ADA gene has been assigned to chromosome 20q12-q13.11 (3).

Mendelian Inheritance: Co-dominant inheritance was observed in two families.

Other Comments: The PCR was performed as previously described (4) with the following modification: (a) denaturation at $94^{\circ} \mathrm{C}$ for $1 \mathrm{~min}$, (b) annealing at $58^{\circ} \mathrm{C}$ for $2 \mathrm{~min}$, (c) extension at $72^{\circ} \mathrm{C}$ for $3 \mathrm{~min}$, and (d) 35 cycles were used. The PCR products were digested with PstI and analyzed on a $9 \%$ polyacrylamide gel (Fig. 1).

Acknowledgement: This study was supported in part by a Grant for Diabetes Research from the Ministry of Health and Welfare.

References: 1) Wiginton,D.A. et al. (1986) Biochemistry 25, 8234-8244. 2) Tzall,S. et al. (1989) Am. J. Hum. Genet. 44, 864-875. 3) Shanwan,S.C. et al. (1989) Cytogenet. Cell Genet. 50, 168-171. 4) Saiki,R.K. et al. (1988) Science 230, 487-491.

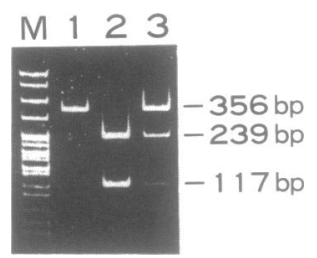

Figure 1. PstI RFLP of the ADA gene detected by PCR. M: molecular weight marker (pBR322 DNA-MspI digest), lane 1: homozygote for A1, lane 2: homozygote for $\mathrm{A} 2$, lane 3: heterozygote for $\mathrm{A} 1 / \mathrm{A} 2$.

\section{Mspl RFLP in the L1 CAM gene in Xq28}

P.J.Willems, L.Vits and K.De Boulle

Department of Medical Genetics, University of Antwerp-

UIA, 2610 Antwerp, Belgium

Description: pHK13 is an EcoRI fragment derived from the human neural adhesion molecule $\operatorname{L1} \operatorname{CAM}(1,2)$.

Polymorphism: MspI detects a two-allele polymorphism with fragment lengths of either $2.5 \mathrm{~kb}$ (allele A1) or $1.9 \mathrm{~kb}$ (allele A2) and constant bands of 1.8 and $1.4 \mathrm{~kb}$.

Frequency: Studied in 154 unrelated Caucasian individuals

$\mathrm{A} 1=0.95$

$\mathrm{A} 2=0.05$

Not Polymorphic For: BamHI, BclI, BglI, EcoRI, HincII, HindIII, PstI, PvuII, SstI, TaqI.

Chromosomal Localization: L1 CAM has been localized to Xq28 by in situ hybridization and pulsed-field gel analysis (1).

Mendelian Inheritance: X-linked inheritance was observed in 2 informative families.

Acknowledgement: We are indebted to B.Jordan for the L1 CAM clone.

References: 1) Djabali,M. et al. (1990) Genomics 7, 587-593. 2) Moos et al. (1988) Nature 334, 701-703.

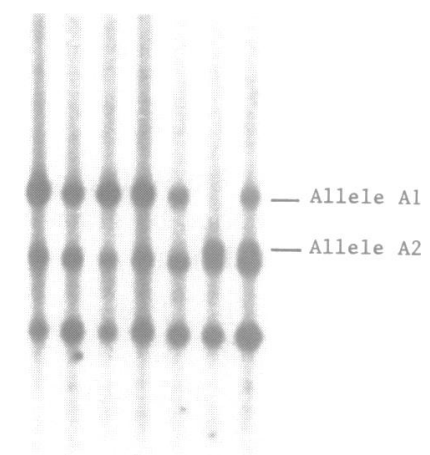

